\title{
Multisensory impairment reported by veterans with and without mild traumatic brain injury history
}

\author{
Terri K. Pogoda, PhD; ${ }^{1-2 *}$ Ann M. Hendricks, PhD; ${ }^{2-3}$ Katherine M. Iverson, PhD; ${ }^{1,4}$ Kelly L. Stolzmann, MS; ${ }^{1}$ \\ Maxine H. Krengel, PhD; ${ }^{5}$ Errol Baker, PhD; ${ }^{1}$ Mark Meterko, PhD; ${ }^{1-2}$ Henry L. Lew, MD, PhD ${ }^{6}$ \\ ${ }^{1}$ Center for Organization, Leadership and Management Research, Department of Veterans Affairs (VA) Boston Healthcare \\ System, Boston, MA; ${ }^{2}$ Department of Health Policy and Management, Boston University School of Public Health, Boston, \\ MA; ${ }^{3}$ Health Care Financing and Economics, VA Boston Healthcare System, Boston, MA; ${ }^{4}$ Women's Health Sciences Divi- \\ sion, National Center for Posttraumatic Stress Disorder, VA Boston Healthcare System, Boston, MA; and Department of \\ Psychiatry, Boston University School of Medicine, Boston, MA; ${ }^{5}$ Research Service, VA Boston Healthcare System, Boston, \\ MA; and Department of Neurology, Boston University School of Medicine, Boston, MA; ${ }^{6}$ University of Hawai'i at Mānoa , \\ John A. Burns School of Medicine, Honolulu, HI; and ${ }^{5}$ Defense and Veterans Brain Injury Center, Richmond, VA
}

\begin{abstract}
With the use of Veterans Health Administration and Department of Defense databases of veterans who completed a Department of Veterans Affairs comprehensive traumatic brain injury (TBI) evaluation, the objectives of this study were to (1) identify the co-occurrence of self-reported auditory, visual, and vestibular impairment, referred to as multisensory impairment (MSI), and (2) examine demographic, deployment-related, and mental health characteristics that were potentially predictive of MSI. Our sample included 13,746 veterans with either a history of deployment-related mild TBI (mTBI) $(n=9,998)$ or no history of TBI $(n=3,748)$. The percentage of MSI across the sample was $13.9 \%$, but was $17.4 \%$ in a subsample with mTBI history that experienced both nonblast and blast injuries. The factors that were significantly predictive of reporting MSI were older age, being female, lower rank, and etiology of injury. Deployment-related mTBI history, posttraumatic stress disorder, and depression were also significantly predictive of reporting MSI, with mTBI history the most robust after adjusting for these conditions. A better comprehension of impairments incurred by deployed servicemembers is needed to fully understand the spectrum of blast and nonblast dysfunction and may allow for more targeted interventions to be developed to address these issues.
\end{abstract}

Key words: Afghanistan, blast injuries, brain injuries, depression, hearing impairment, Iraq, multisensory impairment, nonblast injuries, posttraumatic stress disorder, vestibular impairment, veterans, vision impairment.

\section{INTRODUCTION}

Since 2001, more than 2 million troops have deployed to the Global War on Terrorism (GWOT) in Afghanistan and Iraq [1]. Those serving in Operation Iraqi Freedom/ Operation Enduring Freedom (OIF/OEF) face combat conditions and are vulnerable to injury from roadside bombs and explosive devices [2], as well as nonblast events like gunshots, vehicle accidents, assaults, and falls.

\footnotetext{
Abbreviations: CTBIE = comprehensive traumatic brain injury evaluation, DOD = Department of Defense, DSI = dual sensory impairment, GWOT = Global War on Terrorism, MSI = multisensory impairment, $\mathrm{mTBI}=$ mild traumatic brain injury, NSI-22 = 22-item Neurobehavioral Symptom Inventory, OIF/ OEF = Operation Iraqi Freedom/Operation Enduring Freedom, PTSD = posttraumatic stress disorder, TBI = traumatic brain injury, VA = Department of Veterans Affairs, VHA = Veterans Health Administration.

*Address all correspondence to Terri K. Pogoda, PhD; Center for Organization, Leadership and Management Research, VA Boston Healthcare System, 150 S. Huntington Ave (152M), Boston, MA 02130; 857-364-2626; fax: 857-364-6140. Email: terri.pogoda@va.gov

http://dx.doi.org/10.1682/JRRD.2011.06.0099
} 
Despite improvements that reduce injury and risks of long-term effects from casualties [3-5], up to 19 percent of returning servicemembers are thought to have experienced traumatic brain injury (TBI), the "signature injury" of GWOT [6-9].

A recent study of combat wounds treated at U.S. military medical facilities showed that the proportion of head and neck injuries was higher for OIF/OEF than for prior wars and more than 75 percent of wounds were due to blasts [10]. Almost 50 percent of head and neck injuries were attributable to improvised explosive devices and more than half of combat injuries requiring medical evacuation were due to blasts [11].

Following mild TBI (mTBI), also called concussion, troops may report physical, sensory, cognitive, and behavioral/emotional changes (e.g., headaches, sleep disturbance, impaired vision, memory problems, and irritability) [1213]. Symptoms typically resolve within days or weeks and significant improvement is often seen in 3 months [14-15]. The most visible injuries (e.g., penetrating wounds) understandably receive the most attention in theater, but other symptoms may emerge or be reported later [16], after even a mild injury [17-18]. Scott et al. identified 12 blast-related conditions typically overlooked in patients with polytrauma, including sensory impairments such as hearing loss, tinnitus, vision changes, and vestibular problems [16]. Interviewing patients who have sustained a concussion about current symptoms, which are often underreported, and performing high-yield screening evaluations (e.g., hearing test, officebased balance testing) are recommended [16,19-20].

Dual sensory impairment (DSI) has been documented in OIF/OEF veterans with blast-related TBI who were inpatients at a Department of Veterans Affairs (VA) Polytrauma Rehabilitation Center [7]. Audiologic and visual evaluations indicated that 19 percent had auditory impairment, 34 percent visual impairment, and 32 percent DSI. The largest study to date examining DSI in OIF/OEF veterans documented rates of self-reported impairment in more than 21,000 veterans evaluated for TBI in VA outpatient clinics [8]. In this sample, 9.9 percent reported visual impairment, 31.3 percent auditory impairment, and 34.6 percent DSI. Veterans exposed to blast and evaluated as having a history of TBI made up nearly half the sample and reported the highest rates of DSI (35.4\%). These results suggest a moderate rate of self-reported sensory disturbance among these OIF/OEF veterans.

The auditory system is particularly vulnerable to blasts [21-22]. Primary blast waves involve a high-pressure shock wave followed by a blast wind [2]. Over- or underpressurization of the auditory canal have been major sources of injury that manifest as hearing loss, tinnitus, or vertigo, among other impairments [2,17-18,21,23]. In one study, damage to the ears was the most common single injury type, accounting for approximately 1 in 4 injuries [24]. Hearing impairment associated with combat injury can result in peripheral or central dysfunction [25-29].

Damage to the eyes and visual system has been documented at rates higher than those reported from previous wars [30-32]. Damage can range anywhere from the end organ to the visual cortex, resulting in vision loss or more subtle symptoms of eye fatigue, binocular vision dysfunction, decreased visual acuity, spatial deficits, or decreased levels of reading speed [33-34]. Battle-related eye injuries accounted for 15.8 percent of the in-theater medical evacuations in one study of OIF/OEF soldiers [32]. In another, more than 80 percent of ocular injuries were due to blast fragmentation [31].

Wounded servicemembers also have vestibular problems. Troops with deployment-related mTBI report dizziness (59.3\%) and balance problems (25.9\%) after injuries, but these decline postdeployment (to 5.1\% and 6.4\%, respectively) [23]. Vestibular effects of blasts, however, get worse [35]. Scherer and Schubert documented that troops with blast-induced TBI complained of motion sensitivity, vertigo, gaze instability, migraine-associated dizziness, spatial disorientation, postural instability, and vestibular dysfunction [19]. Recognizing that etiology of TBI may have different effects on pathology, Hoffer et al. performed vestibular testing on patients with blast-related or blunt head trauma [36]. They found that patients differed in responses to vestibular-ocular and vestibular-spinal testing and recommended that mechanism of injury be considered when managing vestibular symptoms.

Normal hearing, vision, and balance and coordination are important for performing activities of daily living, psychosocial functioning, leisure activities, and employment [7,37-42] and are necessary for communication and rehabilitation. A growing literature suggests auditory, visual, and vestibular symptoms are common among OIF/OEF veterans who have experienced TBI, but no studies to date have examined the coexistence of these symptoms in a large cohort. Using national data from the Veterans Health Administration (VHA) and Department of Defense (DOD), our exploratory aims were to (1) identify the co-occurrence of auditory, visual, and vestibular impairment, referred to here as multisensory impairment (MSI), 
in OIF/OEF veterans who completed a VA comprehensive TBI evaluation (CTBIE) and (2) examine demographic, deployment-related, and mental health characteristics that were potentially predictive of MSI.

\section{METHODS}

\section{Design}

A retrospective database study of veterans completing a VA CTBIE between October 2007 and June 2009 was performed. Military service data are from the Defense Management Data Center.

\section{Participants and Mild Traumatic Brain Injury History Designation}

VA is mandated to screen for TBI in all OIF/OEF veterans seeking VA healthcare. Of those who are screened, approximately 20 percent screen positive for TBI [43] and are offered an opportunity for a CTBIE (described subsequently). Among 36,214 VHA electronic CTBIE records, we selected patients who did not report brain injury either predeployment or since returning from deployment (postdeployment) $(n=21,627)$. Of patients who were evaluated by a VA clinician as having experienced TBI, the sample was further restricted to those who met criteria for mTBI history based on VA-DOD clinical practice guidelines consistent with American Congress of Rehabilitation Medicine [44] criteria. mTBI history was determined by self-reports of alteration or loss of consciousness, posttraumatic amnesia, and these conditions' respective durations [45]. The data did not include a Glasgow Coma Scale rating or neuroimaging to classify severity. Patients who reported being "uncertain" of having experienced any of the three postinjury sequelae (i.e., alteration or loss of consciousness or posttraumatic amnesia) but still reported experiencing at least one of these events within the specified duration [45] were categorized as having experienced an mTBI. The final sample $(N=13,746)$ consisted of patients with VA clinician-confirmed deployment-related mTBI history $(n=9,998)$ and a comparison group of patients with no history of TBI $(n=3,748)$ (Figure 1).

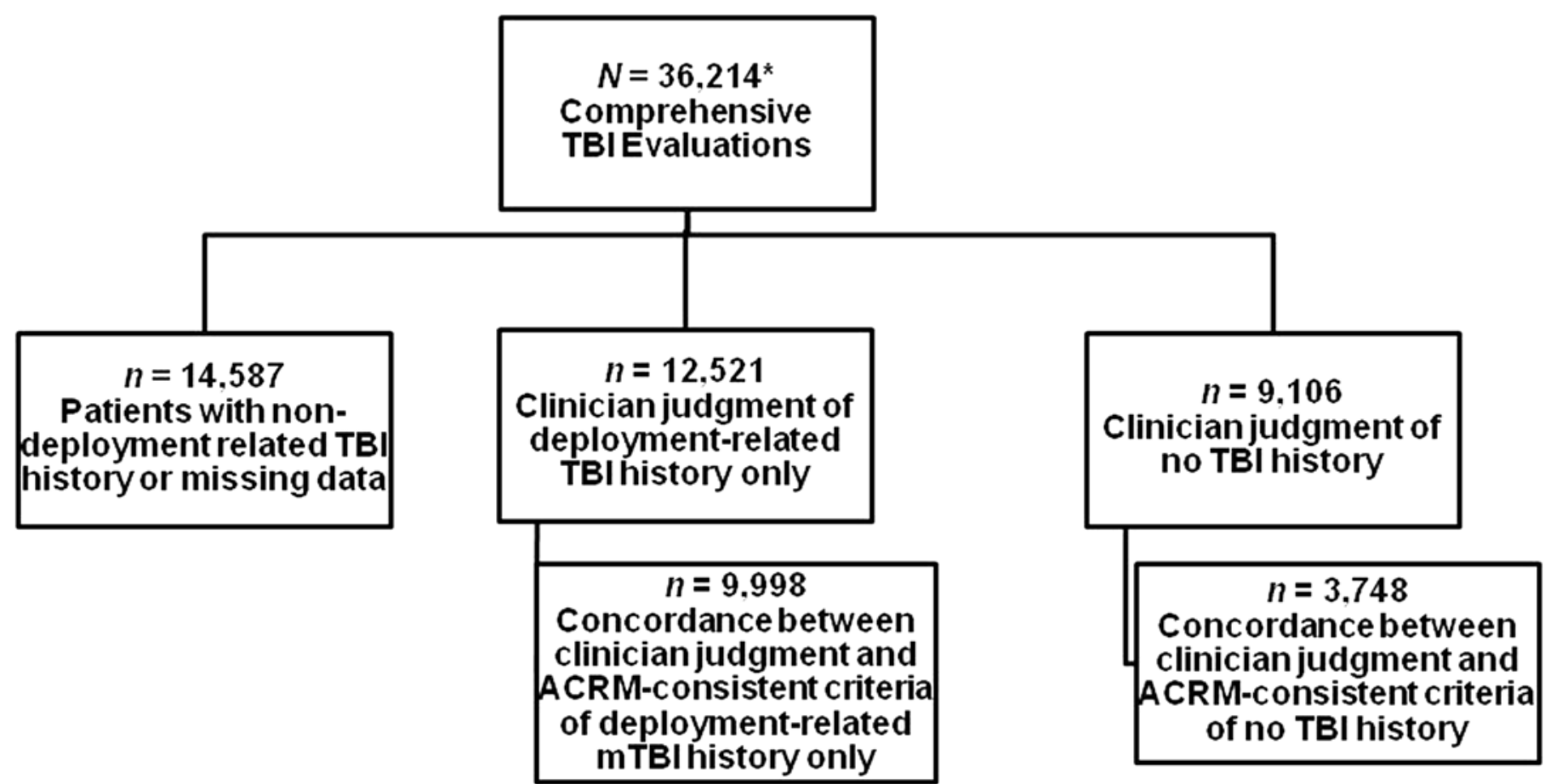

Figure 1.

Determination of final sample of patients. "Excludes 518 test cases or repeat comprehensive traumatic brain injury (TBI) evaluations and 187 cases with inconsistent blast responses (85 from deployment-related TBI history only and 102 from no history of TBI groups). $\mathrm{ACRM}=$ American Congress of Rehabilitation Medicine, $\mathrm{mTBI}=$ mild TBI. 


\section{Psychiatric Diagnoses}

As described elsewhere [46], International Classification of Diseases, 9th Revision, Clinical Modification [47] diagnostic codes in VHA administrative data for posttraumatic stress disorder (PTSD) and depression were used to identify these common disorders documented in OIF/OEF veterans [6,46,48-49]. We limited this identification to codes assigned in two or more encounters [48] in primary care, mental health, women's health, or rehabilitation clinics or from an inpatient stay during fiscal years 2007-2009.

\section{Comprehensive Traumatic Brain Injury Evaluation Instrument}

The CTBIE template and process is described in detail elsewhere [8,43]. Briefly, the evaluation is performed by a VA clinician and reviews the veteran's medical history; blast and nonblast deployment-related experiences that may have led to injury; current symptoms that may be related to those experiences; a physical examination; and a determination by the clinician of whether the patient had experienced a TBI and, if so, continues to have residual symptoms.

The 22-item Neurobehavioral Symptom Inventory (NSI-22) [12], a patient self-report checklist, is administered during the CTBIE. Patients rate the extent to which each symptom has affected them in the past $30 \mathrm{~d}$. The 5point Likert scale ranges from 0 (none) to 4 (very severe). We were interested in patients who self-reported coexisting auditory, visual, and vestibular symptoms. For purposes of this study, as in prior work [8], we considered symptoms reported as at least a 2 (moderate) indicative of impairment. The NSI-22 items "hearing difficulty" and "vision problems, blurring, trouble seeing" were used to characterize auditory and visual impairment, respectively. Vestibular symptoms were defined as a combination of the NSI-22 items “feeling dizzy," "loss of balance," and "poor coordination, clumsy." This was based on a factor analysis performed on the same data set in which these three symptoms loaded as a separate factor [50]. For ease of phrasing, "vestibular" was used as an umbrella term to encompass the three aforementioned symptoms, but we acknowledge that these symptoms may not physiologically derive from the inner ear (vestibule) and could be either peripheral or central in origin [29]. An a priori decision was made to compute vestibular scores only for patients who answered at least two of the three vestibularrelated questions. In our final sample, no patients were excluded based on this criterion. Reporting a 2 (denoting at least moderate impairment) or higher was considered indicative of vestibular impairment. Patients who reported a 2 or higher on all symptoms related to auditory, visual, and vestibular impairment were classified as having MSI.

\section{Data Analysis Strategy}

\section{Sample Characteristics}

Data analyses used SPSS software, version 18.0 (IBM Corp; Armonk, New York). For characterization of the sample, we calculated and stratified by mTBI history based on concordance between clinician judgment and ACRM-consistent criteria of deployment-related mTBI history only the frequencies and percentages for categorical variables and mean and standard deviation values for quantitative variables. To examine whether the sample differed on demographic (e.g., sex, age), deploymentrelated (e.g., branch of service, etiology of injury), and mental health (e.g., PTSD, depression) variables as a function of mTBI history, we performed a chi-square test of association or an independent $t$-test based on the dependent variable's unit of measurement.

\section{Logistic Regression Analyses}

Three sets of logistic regressions were performed to predict MSI. For the first, each demographic, deploymentrelated, and mental health variable was entered separately to determine whether each was independently predictive of MSI prior to all factors being entered simultaneously. In the second, all variables except PTSD and depression were entered simultaneously to explore potential predictors of MSI when adjusting for other factors. For the final logistic regression analysis, all demographic, deploymentrelated, and mental health variables were entered into the analysis simultaneously to determine whether including PTSD and depression influenced the effects of the other variables in predicting MSI. Unadjusted and adjusted odds ratios and 95 percent confidence intervals are reported for each analysis.

\section{RESULTS}

\section{Demographics and Deployment-Related Events as Functions of Deployment-Related Mild Traumatic Brain Injury History}

Characteristics of the sample are stratified by deployment-related history of mTBI in Table 1. The 
Table 1.

Demographic, deployment-related, and mental health characteristics (\%) of Operation Iraqi Freedom/Operation Enduring Freedom veteran sample, stratified by deployment-related mild traumatic brain injury (mTBI) history.

\begin{tabular}{|c|c|c|c|c|c|}
\hline Factor & $\begin{array}{c}\text { Total } \\
(N=13,746)\end{array}$ & $\begin{array}{c}\text { mTBI } \\
(n=9,998)\end{array}$ & $\begin{array}{c}\text { No mTBI } \\
(n=3,748)\end{array}$ & $\chi^{2}$ & $p$-Value \\
\hline Age (range: $18-64$ yr) & & & & 272.52 & $<0.001$ \\
\hline $18-24$ & 21.6 & 23.7 & 16.1 & & \\
\hline $25-29$ & 34.3 & 35.9 & 30.0 & & \\
\hline $30-39$ & 24.5 & 23.8 & 26.3 & & \\
\hline$\geq 40$ & 19.6 & 16.6 & 27.6 & & \\
\hline Sex & & & & 55.35 & $<0.001$ \\
\hline Female & 5.9 & 5.0 & 8.4 & & \\
\hline Male & 94.1 & 95.0 & 91.6 & & \\
\hline Branch of Service & & & & 53.69 & $<0.001$ \\
\hline Army & 74.1 & 73.3 & 76.2 & & \\
\hline Marine Corps & 17.9 & 19.2 & 14.3 & & \\
\hline Other (Air Force, Navy, Coast Guard) & 8.0 & 7.5 & 9.5 & & \\
\hline Rank $^{*}$ & & & & 86.30 & $<0.001$ \\
\hline Junior Enlisted (E1-E4) & 49.8 & 51.7 & 44.7 & & \\
\hline Midlevel Enlisted (E5-E6) & 39.6 & 38.9 & 41.4 & & \\
\hline Senior Enlisted \& Officers & 10.6 & 9.3 & 14.0 & & \\
\hline Etiology of Injury & & & & $1,224.64$ & $<0.001$ \\
\hline None Reported & 10.4 & 5.5 & 23.5 & & \\
\hline$\geq 1$ Nonblast Only & 15.2 & 14.1 & 18.0 & & \\
\hline$\geq 1$ Blast Only & 44.3 & 45.1 & 42.3 & & \\
\hline 1 Nonblast \& 1 Blast & 5.3 & 6.0 & 3.5 & & \\
\hline >1 Nonblast \& 1 Blast & 2.7 & 3.2 & 1.7 & & \\
\hline 1 Nonblast $\&>1$ Blast & 8.6 & 9.8 & 5.4 & & \\
\hline$>1$ Nonblast $\&>1$ Blast & 13.5 & 16.4 & 5.7 & & \\
\hline PTSD & 62.1 & 66.6 & 49.9 & 318.00 & $<0.001$ \\
\hline Depression & 32.4 & 32.7 & 31.7 & 1.18 & 0.28 \\
\hline
\end{tabular}

average patient was male, $31.4 \pm 8.7 \mathrm{yr}$ old, and served in the Army. Patients with mTBI history were significantly younger $(30.6 \pm 8.2$ vs $33.5 \pm 9.5$; $t(13,738)=17.46, p<$ 0.001), with about one-third 25-29 yr; male; in the Army; junior enlisted (ranks of E1-4); and injured in at least one blast (80.5\%), although 49.5 percent experienced at least one nonblast injury. Injury by blast only was common for both patient groups (mTBI history: 45.1\%, no mTBI history: 42.3\%). Patients with deployment-related mTBI history were more than 2.5 times more likely to experience both multiple nonblast and blast injuries. PTSD was significantly associated with mTBI, as two-thirds of patients with mTBI were diagnosed with PTSD compared with one-half of patients without mTBI history. Depression, documented in one- third of the sample, did not vary as a function of mTBI history.

\section{Co-Occurrence of Auditory, Visual, and Vestibular Impairment}

We examined the coexistence of self-reported moderate to very severe auditory, visual, and vestibular impairment among the 13,746 OIF/OEF veterans in our final sample. Across all patients, we found that all three sensory impairment domains were significantly associated with one another (all $\left.\chi^{2}(1)>700.00, p<0.001\right)$. The overall rates of sensory impairment (either alone or in combination with others) was 61.1 percent for auditory, 40.3 percent for visual, and 22.4 percent for vestibular. The overall co-occurrence of MSI was 13.9 percent (Figure 2). 


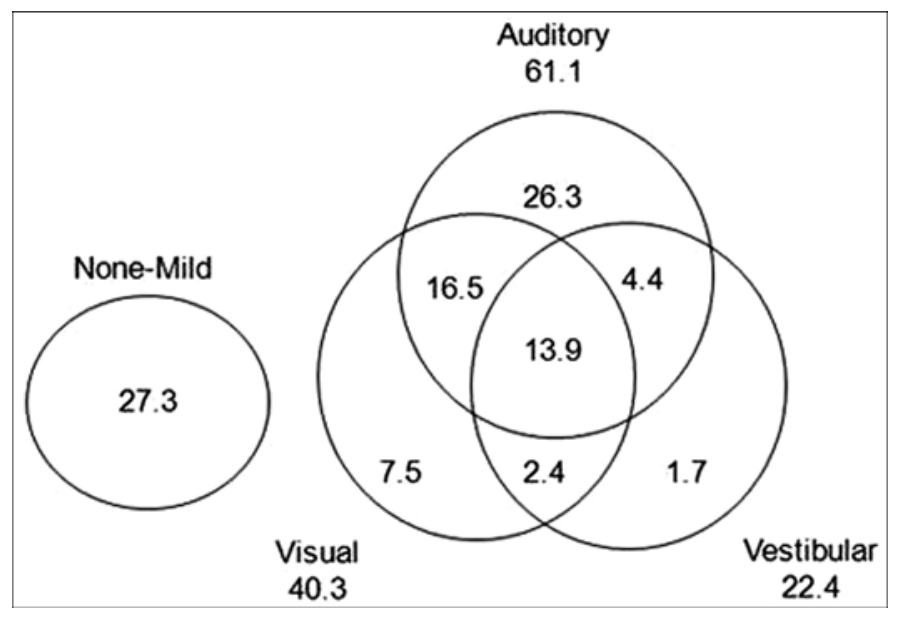

Figure 2.

Distribution (\%) of patient-reported sensory impairment.

An earlier study found that the rate of DSI varied with TBI history and blast exposure [8]. To determine whether a similar pattern existed for MSI, we stratified patients by mTBI history and etiology of injury (blast, nonblast, or both). Inspection of the frequencies (Figure 3) shows that MSI was more common among patients with a history of deployment-related mTBI and occurred most frequently in patients reporting both nonblast and blast injuries and least in those with blast injuries only. Patients evaluated as having deployment-related mTBI and both nonblast and blast injuries $(n=4,542)$ had the highest rate of MSI (17.4\%).

\section{Logistic Regression Models}

\section{Model 1: Individual Variables Predicting Multisensory Impairment}

Unadjusted logistic regressions with individual demographic, deployment-related, and mental health variables showed they were independently predictive of MSI (Table 2). The odds for reporting symptoms of MSI increased steadily as a function of age group, with patients 40 and older being more than 2 times more likely to report MSI than those 18 to 24 yr. Females were 1.29 times more likely than males to report MSI symptoms. For branch of service, those who served in the Army and Other (Air Force, Navy, or Coast Guard) services were more likely to report MSI than those who served in the Marines. Compared with Veterans who did not specify etiology of injury, those who reported experiencing both multiple nonblast and blast injuries were 1.61 times more likely to report symptoms of MSI. History of deployment-related

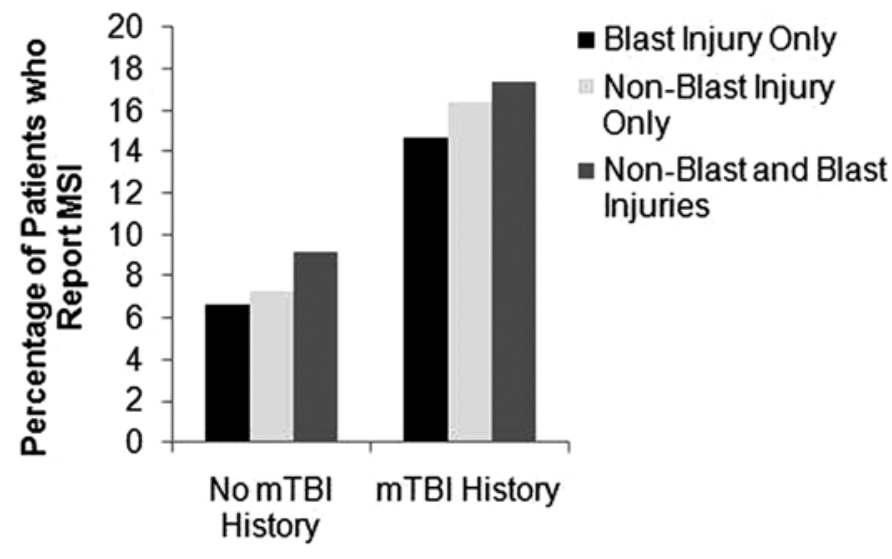

Figure 3.

Patient-reported multisensory impairment (MSI) as function of injury etiology. $\mathrm{mTBI}=$ mild traumatic brain injury.

mTBI and diagnoses of PTSD and depression were also predictive of MSI. MSI did not differ by rank, which was significantly associated with age $\left(\chi^{2}(6)=4420.00, p<\right.$ $0.001)$. The majority of senior enlisted and officers (73.5\%) were $40 \mathrm{yr}$ and older, whereas the majority of the junior enlisted were between the ages of 18 and $29 \mathrm{yr}$ (74.4\%).

Model 2: Demographic and Deployment-Related Variables Before Mental Health Variable Inclusion

Entering demographic and deployment-related characteristics simultaneously into a logistic regression predicting MSI yielded a significant model $\left(\chi^{2}(15)=\right.$ 416.20, $p<0.001)$. After adjusting for all other factors, significant predictors of MSI included older age, being female, lower rank, injury etiology, and mTBI history (Table 2). Regarding etiology of injury, veterans who reported experiencing both multiple nonblast and blast injuries were more than 1.5 times more like to report symptoms of MSI than those who did not report injury etiology. A history of mTBI was the strongest predictor of MSI, with patients with mTBI history approximately 2.5 times more likely than patients without mTBI history to report MSI symptoms $(p<0.001)$.

Model 3: Demographic, Deployment-Related, and Mental Health Variables

To determine whether PTSD or depression influenced the predictability of MSI, we simultaneously entered demographic, deployment-related, and mental health variables into a final logistic regression analysis, resulting in a 
Table 2.

Unadjusted and adjusted odds ratios (ORs) for predicting multisensory impairment.

\begin{tabular}{|c|c|c|c|c|c|c|}
\hline \multirow{2}{*}{ Predictor Variable } & \multicolumn{2}{|c|}{$\begin{array}{l}\text { Model 1: Individual } \\
\text { Predictors }\end{array}$} & \multicolumn{2}{|c|}{$\begin{array}{c}\text { Model 2: Excludes PTSD } \\
\text { \& Depression }\end{array}$} & \multicolumn{2}{|c|}{$\begin{array}{c}\text { Model 3: Includes PTSD } \\
\text { \& Depression }\end{array}$} \\
\hline & $\begin{array}{l}\text { Unadjusted OR } \\
\quad(95 \% \mathrm{CI})\end{array}$ & $p$-Value & $\begin{array}{l}\text { Adjusted OR } \\
(95 \% \mathrm{CI})\end{array}$ & $p$-Value & $\begin{array}{l}\text { Adjusted OR } \\
(95 \% \mathrm{CI})\end{array}$ & $p$-Value \\
\hline Age (yr) & & $<0.001$ & & $<0.001$ & & $<0.001$ \\
\hline \multicolumn{7}{|l|}{$18-24$} \\
\hline $25-29$ & $1.43(1.23-1.66)$ & $<0.001$ & $1.50(1.29-1.75)$ & $<0.001$ & $1.44(1.24-1.68)$ & $<0.001$ \\
\hline $30-39$ & 1.69 (1.45-1.97) & $<0.001$ & $1.97(1.67-2.32)$ & $<0.001$ & $1.82(1.54-2.15)$ & $<0.001$ \\
\hline$\geq 40$ & $2.23(1.90-2.60)$ & $<0.001$ & $3.21(2.66-3.87)$ & $<0.001$ & 2.89 (2.38-3.49) & $<0.001$ \\
\hline Female (vs Male) & $1.29(1.07-1.56)$ & 0.008 & 1.42 (1.17-1.73) & 0.001 & $1.41(1.15-1.72)$ & 0.001 \\
\hline Branch of Service & & $<0.001$ & & 0.34 & & 0.55 \\
\hline Army & 1.35 (1.18-1.55) & 0.001 & $1.11(0.96-1.28)$ & 0.17 & $1.08(0.94-1.26)$ & 0.29 \\
\hline \multicolumn{7}{|l|}{ Marine Corps } \\
\hline $\begin{array}{l}\text { Other (Air Force, Navy, } \\
\text { Coast Guard) }\end{array}$ & $1.29(1.04-1.60)$ & 0.02 & $1.04(0.83-1.30)$ & 0.75 & $1.10(0.88-1.38)$ & 0.41 \\
\hline Rank & & 0.69 & & $<0.001$ & & 0.001 \\
\hline Junior Enlisted (E1-E4) & $0.94(0.80-1.10)$ & 0.44 & $1.63(1.35-1.98)$ & $<0.001$ & $1.44(1.18-1.75)$ & $<0.001$ \\
\hline Midlevel Enlisted (E5-E6) & $0.93(0.79-1.10)$ & 0.39 & $1.31(1.09-1.57)$ & 0.004 & $1.22(1.02-1.47)$ & 0.03 \\
\hline \multicolumn{7}{|l|}{ Senior Enlisted \& Officers } \\
\hline Etiology of Injury & & $<0.001$ & & $<0.001$ & & $<0.001$ \\
\hline \multicolumn{7}{|l|}{ None Reported } \\
\hline$\geq 1$ Nonblast Only & $1.40(1.13-1.73)$ & 0.002 & $1.00(0.80-1.25)$ & 0.99 & $1.06(0.85-1.32)$ & 0.63 \\
\hline$\geq 1$ Blast Only & $1.26(1.05-1.52)$ & 0.015 & $1.03(0.84-1.25)$ & 0.81 & $0.99(0.81-1.21)$ & 0.91 \\
\hline 1 Nonblast \& 1 Blast & $1.58(1.21-2.05)$ & 0.001 & $1.14(0.87-1.50)$ & 0.35 & $1.11(0.84-1.46)$ & 0.47 \\
\hline$>1$ Nonblast \& 1 Blast & $1.42(1.01-1.98)$ & 0.04 & $1.03(0.73-1.45)$ & 0.88 & $1.00(0.70-1.42)$ & 0.98 \\
\hline 1 Nonblast $\&>1$ Blast & $1.33(1.05-1.69)$ & 0.02 & $0.99(0.77-1.27)$ & 0.92 & $0.94(0.73-1.21)$ & 0.61 \\
\hline$>1$ Nonblast $\&>1$ Blast & $2.19(1.78-2.68)$ & $<0.001$ & $1.61(1.30-2.00)$ & $<0.001$ & $1.52(1.22-1.89)$ & $<0.001$ \\
\hline mTBI History & $2.30(2.02-2.63)$ & $<0.001$ & $2.44(2.13-2.81)$ & $<0.001$ & $2.22(1.93-2.56)$ & $<0.001$ \\
\hline PTSD & $2.42(2.16-2.71)$ & $<0.001$ & - & - & $2.00(1.77-2.26)$ & $<0.001$ \\
\hline Depression & 1.80 (1.63-1.99) & $<0.001$ & - & - & 1.39 (1.25-1.54) & $<0.001$ \\
\hline
\end{tabular}

significant model $\left(\chi^{2}(17)=632.71, p<0.001\right)$ (Table 2). The predictors that were significant before the inclusion of mental health variables remained significantly predictive of reporting MSI. Patients with PTSD or depression were 2.00 times and 1.39 times more likely, respectively, to report symptoms of MSI. After accounting for these mental health conditions, the effect of mTBI history was slightly attenuated compared with the previous model (2.22 vs 2.44), but continued to remain robust and was one of the model's strongest predictors of reporting MSI.

\section{DISCUSSION}

MSI can impair a patient's ability to communicate and interact with the environment [7], limiting instrumental, emotional, social, occupational, and academic functioning. MSI can also be detrimental because of the inability to compensate for deficits in one sensory modality by relying on other sensory inputs [51]. Our analysis of OIF/OEF veterans who completed a VA CTBIE and were judged to have deployment-related mTBI only or no history of mTBI ( $n=13,746)$ sought to identify the co-occurrence of subjectively reported moderate to very severe auditory, visual, and vestibular symptoms and examine what demographic, deployment-related, and mental health factors were predictive of MSI. After simultaneously accounting for demographics, deployment-related events, PTSD, and depression, we found that the factors that were significantly predictive of MSI were older age, being female, lower rank, deployment-related injury and mTBI history, PTSD, and depression. 
The rate of patient-reported MSI across the entire sample was 13.9 percent. MSI reporting increased steadily as a function of age. The strongest predictor of reporting MSI was being $40 \mathrm{yr}$ or older, because this age group was nearly 3 times more likely to report MSI symptoms than patients who were 18 to $24 \mathrm{yr}$. Decline in hearing and vision is common as people age [37,39-42], but concurrent hearing and vision impairment is typically documented in patients $70 \mathrm{yr}$ and older [39-42]. In one chart review of veterans who were receiving regular outpatient hearing and vision care, 0 percent of the veterans $65 \mathrm{yr}$ and younger were judged to have DSI and, among those who were 75 to $84 \mathrm{yr}$, only 9 percent had documented DSI [37]. However, nearly 14 percent of the present study sample, whose average age was $31.4 \mathrm{yr}$, reported symptoms of MSI. This rate increased to 17.4 percent for the subset of patients with mTBI history who experienced both nonblast and blast injuries. Smith et al.'s study [37] included professional assessment of sensory impairment and operationally defined DSI by using standardized clinical criteria, whereas the present study was based on patient self-report only; thus, any comparison of findings needs to be interpreted cautiously. If professional assessment of the present sample were to confirm the patient self-report of sensory impairment, these results would suggest that MSI is appearing prematurely in OIF/OEF veterans, particularly those with TBI who experienced multiple injuries. Future prospective, longitudinal research is recommended to evaluate this possibility.

That junior enlistees were more likely than senior servicemembers to report MSI is consistent with junior servicemembers being more likely to be assigned to frontlines and potentially exposed to riskier military conditions. However, because junior military personnel are younger, they may differ from senior servicemembers in other ways that could affect their reporting of symptoms. For example, different generational attitudes, career paths, or interest in qualifying for postseparation benefits could all contribute to willingness for junior servicemembers to report multiple symptoms.

After accounting for all other factors, female veterans were approximately 45 percent more likely than males to report symptoms of MSI, even though women comprised only 6 percent of the sample. Women are serving in the military at unprecedented rates [52] and have expanded occupational functions during deployments [53]. U.S. female servicemembers are restricted from being assigned to frontline combat units, but do partici- pate in self-defense missions that may "have features of direct combat" [54, p. 65]. In light of previous research with medical and community samples demonstrating that women tend to report more numerous, intense, and frequent somatic symptoms relative to men [55-58], further research is needed to determine whether these results are due to objective differences between female and male veterans or attributable to an over- or underreporting of symptoms. These findings nonetheless suggest that special attention should be paid to women with deploymentrelated mTBI history [46].

Deployment-related mTBI history, PTSD, and depression were each independently predictive of reporting MSI symptoms. When entered into the same model simultaneously along with other factors, each remained a significant predictor, with mTBI history the most robust. PTSD and depression have been well documented in OIF/OEF veterans $[6,23,48-49,59-67]$. This is a notable finding because other studies have found diminished effects of TBI when PTSD and depressive symptom severity were taken into account $[6,62]$. A major difference between these studies and the present results is our outcome variable: concurrent auditory, visual, and vestibular symptoms reported to cause at least moderate impairment. To our knowledge, this specific cluster of multisensory symptoms has never been studied in OIF/OEF veterans. As noted earlier, the nature of the combat and deployment training [68], increased exposure to explosive weaponry, and general military conditions leave servicemembers vulnerable to different mechanisms of injury, which may account for our findings.

Like Lippa and colleagues [62], we did not find support for any one etiology of injury (blast or nonblast) being more significant for reporting MSI symptoms. Instead, frequency of injury seemed to be a major contributor. When studied independently, experiencing multiple blast and nonblast injuries resulted in the greatest likelihood of reporting MSI symptoms. Given the cumulative effect of multiple head injuries, as suggested by the sports concussion literature [69-71], experiencing blast and nonblast injury only once may allow for a better recovery from each injury compared with individuals with multiple injury events. Experiencing the same injury type more than once may have cumulative effects, because the previous injury symptoms may not have fully resolved [72-74]. This may also account for why age was a predictor of MSI, because older servicemembers may have experienced more injuries or adverse military conditions over the course of their military careers. However, without more detail about the 
nature, timing, and severity of the injuries, these hypotheses are simple conjecture. As Lippa and colleagues offer [62], the effects of blast versus nonblast injuries may be more similar than they are different.

\section{LIMITATIONS}

There are several limitations to the present study. Primarily, the MSI symptoms were self-reported. In the absence of a professional evaluation of this symptom cluster, we do not know the extent to which MSI exists and whether any deficiencies are peripheral or central in nature.

The current results may not be generalizable to all OIF/OEF veterans, because the sample was comprised of veterans who sought VA healthcare services, screened positive for TBI, and completed a VA CTBIE. We are not certain how MSI rates found in this study compare with those of veterans receiving non-VA healthcare or not utilizing healthcare services. Among veterans with TBI history, we focused only on those classified as mTBI. Thus, our results may not generalize to patients with moderate or severe TBI. Finally, we do not have comprehensive information on when injuries occurred and, thus, could not consistently control for time since injury.

Although it is impossible to state with certainty, patients likely did not have MSI before deployment, because this condition would have likely made servicemembers medically unfit to deploy or serve in the military [75]. However, we do not know whether MSI is attributable exclusively to deployment experiences or whether events between deployment and the CTBIE also affected sensory systems. For example, many OIF/OEF veterans with mTBI also have comorbid physical and psychiatric conditions [46]. These conditions themselves, or the medications prescribed to treat them [29], may negatively affect the visual, auditory, and vestibular systems.

\section{CONCLUSIONS AND IMPLICATIONS}

With the use of a large database sample of 13,746 OIF/ OEF veterans, the co-occurrence of self-reported MSI was identified in 13.9 percent and increased to 17.4 percent for patients who reported experiencing both nonblast and blast injuries and were evaluated as having a history of deployment-related mTBI. After demographics, deployment- related events, and psychiatric conditions were simultaneously accounted for, the factors that were significantly predictive of MSI were older age, being female, lower rank, experiencing both multiple nonblast and blast injuries, deployment-related mTBI history, PTSD, and depression.

Because of the degree of symptom overlap between TBI and psychiatric disorders [46,61,63-64,66,76-80], clinicians evaluating TBI also should determine whether mental health conditions are present to decide on the best course of treatment $[6,62]$. Patients with MSI may benefit from a team-based approach to care [63-64,77-78]. As discussed elsewhere [7], the VA CTBIE process and NSI-22 allow clinicians, at a glance, to survey symptoms that patients endorse as being disruptive to their daily functioning, obtain a better history of the nature of the problem(s), and decide what type of follow-up care is warranted. A better comprehension of physical and psychological injuries sustained by servicemembers exposed to general combat conditions, blast, and nonblast injuries is needed to fully understand the spectrum of dysfunction and may allow clinicians to develop more targeted interventions to address these issues.

\section{ACKNOWLEDGMENTS}

\section{Author Contributions:}

Study concept and design: T. K. Pogoda, A. M. Hendricks, E. Baker, M. Meterko, H. L. Lew.

Data analysis and interpretation: T. K. Pogoda, A. M. Hendricks, K. M. Iverson, K. L. Stolzmann, M. H. Krengel, E. Baker,

M. Meterko, H. L. Lew.

Writing of manuscript: T. K. Pogoda, A. M. Hendricks, K. M. Iverson, E. Baker, M. Meterko, H. L. Lew.

Critical revision of manuscript: T. K. Pogoda, A. M. Hendricks, K. M. Iverson, K. L. Stolzmann, M. H. Krengel, E. Baker, M. Meterko, H. L. Lew.

Final approval of version to be published: T. K. Pogoda, A. M. Hendricks, K. M. Iverson, K. L. Stolzmann, M. H. Krengel, E. Baker, M. Meterko, H. L. Lew.

Obtained funding: A. M. Hendricks, H. L. Lew.

Financial Disclosures: The authors have declared that no competing interests exist.

Funding/Support: This article was based on work supported by the VA Office of Research and Development, Health Services Research and Development Service (grant SDR 08-405).

Additional Contributions: The authors wish to thank John A. Gardner, $\mathrm{PhD}$, for his contribution to data analysis and interpretation.

Institutional Review: The study was reviewed and approved by the institutional review board of the VA Boston Healthcare System.

Participant Follow-Up: The authors do not plan to inform database participants of the publication of this study. 
Disclaimer: The opinions expressed in this article are the authors' and do not reflect those of the VA, the VHA, the Health Services Research and Development Service, the Defense and Veterans Brain Injury Center, or the DOD.

\section{REFERENCES}

1. White House. Strengthening our military families: meeting America's commitment. Washington (DC): Department of Defense; 2011.

2. DePalma RG, Burris DG, Champion HR, Hodgson MJ. Blast injuries. N Engl J Med. 2005;352(13):1335-42. [PMID:15800229] http://dx.doi.org/10.1056/NEJMra042083

3. Brewin B. Pentagon orders system to track soldiers for brain injuries. Nextgov [Internet]. 2010 Jun. Available from: http:// www.nextgov.com/nextgov/ng 20100625 1969.php\#

4. Okie S. Traumatic brain injury in the war zone. N Engl J Med. 2005;352(20):2043-47. [PMID:15901856] http://dx.doi.org/10.1056/NEJMp058102

5. Warden D. Military TBI during the Iraq and Afghanistan wars. J Head Trauma Rehabil. 2006;21(5):398-402. [PMID:16983225] http://dx.doi.org/10.1097/00001199-200609000-00004

6. Hoge CW, McGurk D, Thomas JL, Cox AL, Engel CC, Castro CA. Mild traumatic brain injury in U.S. soldiers returning from Iraq. N Engl J Med. 2008;358(5):453-63. [PMID:18234750] http://dx.doi.org/10.1056/NEJMoa072972

7. Lew HL, Garvert DW, Pogoda TK, Hsu PT, Devine JM, White DK, Myers PJ, Goodrich GL. Auditory and visual impairments in patients with blast-related traumatic brain injury: Effect of dual sensory impairment on Functional Independence Measure. J Rehabil Res Dev. 2009;46(6): 819-26. [PMID:20104405] http://dx.doi.org/10.1682/JRRD.2008.09.0129

8. Lew HL, Pogoda TK, Baker E, Stolzmann KL, Meterko M, Cifu DX, Amara J, Hendricks AM. Prevalence of dual sensory impairment and its association with traumatic brain injury and blast exposure in OEF/OIF veterans. J Head Trauma Rehabil. 2011;26(6):489-96. [PMID:21386715] http://dx.doi.org/10.1097/HTR.0b013e318204e54b

9. Tanielian T, Jaycox LH. Invisible wounds of war: psychological and cognitive injuries, their consequences, and services to assist recovery. Santa Monica (CA): RAND Corporation; 2008. p. 492.

10. Owens BD, Kragh JF Jr, Wenke JC, Macaitis J, Wade CE, Holcomb JB. Combat wounds in Operation Iraqi Freedom and Operation Enduring Freedom. J Trauma. 2008;64(2): 295-99. [PMID:18301189] http://dx.doi.org/10.1097/TA.0b013e318163b875
11. Chandler CW. Blast-related ear injury in current U.S. military operations: role of audiology on the interdisciplinary team. The ASHA Leader [Internet]. 2006 Jul 11. Available from: http://www.asha.org/Publications/leader/2006/060711/ f060711a2/

12. Cicerone KD, Kalmar K. Persistent postconcussion syndrome: The structure of subjective complaints after mild traumatic brain injury. J Head Trauma Rehabil. 1995;10(3):1-17. http://dx.doi.org/10.1097/00001199-199510030-00002

13. Benge JF, Pastorek NJ, Thornton GM. Postconcussive symptoms in OEF-OIF veterans: factor structure and impact of posttraumatic stress. Rehabil Psychol. 2009;54(3):270-78. [PMID:19702425] http://dx.doi.org/10.1037/a0016736

14. Defense and Veterans Brain Injury Center. TBI facts. Washington (DC): Department of Defense; 2009.

15. Belanger HG, Vanderploeg RD. The neuropsychological impact of sports-related concussion: a meta-analysis. J Int Neuropsychol Soc. 2005;11(4):345-57. [PMID:16209414]

16. Scott SG, Belanger HG, Vanderploeg RD, Massengale J, Scholten J. Mechanism-of-injury approach to evaluating patients with blast-related polytrauma. J Am Osteopath Assoc. 2006;106(5):265-70. [PMID:16717367]

17. Kushner D. Mild traumatic brain injury: toward understanding manifestations and treatment. Arch Intern Med. 1998;158(15):1617-24. [PMID:9701095] http://dx.doi.org/10.1001/archinte.158.15.1617

18. Centers for Disease Control and Prevention. Injury prevention and control: traumatic brain injury. Centers for Disease Control and Prevention [Internet]. 2010 Mar 8. Available from: http://www.cdc.gov/concussion/signs_symptoms.html

19. Scherer MR, Schubert MC. Traumatic brain injury and vestibular pathology as a comorbidity after blast exposure. Phys Ther. 2009;89(9):980-92. [PMID:19628578] http://dx.doi.org/10.2522/ptj.20080353

20. Hoffer ME, Balough BJ, Gottshall KR. Posttraumatic balance disorders. Int Tinnitus J. 2007;13(1):69-72. [PMID:17691667]

21. Cohen JT, Ziv G, Bloom J, Zikk D, Rapoport Y, Himmelfarb MZ. Blast injury of the ear in a confined space explosion: auditory and vestibular evaluation. Isr Med Assoc J. 2002; 4(7):559-62. [PMID:12120473]

22. Centers for Disease Control and Prevention. Blast injuries: ear blast Injuries [Internet]. Atlanta (GA): Centers for Disease Control and Prevention; 2008 May 12. Available from: http://www.bt.cdc.gov/masscasualties/blastinjury-ear.asp

23. Terrio H, Brenner LA, Ivins BJ, Cho JM, Helmick K, Schwab K, Scally K, Bretthauer R, Warden D. Traumatic brain injury screening: preliminary findings in a US Army Brigade Combat Team. J Head Trauma Rehabil. 2009; 24(1):14-23. [PMID:19158592] http://dx.doi.org/10.1097/HTR.0b013e31819581d8 
24. Gondusky JS, Reiter MP. Protecting military convoys in Iraq: an examination of battle injuries sustained by a mechanized battalion during Operation Iraqi Freedom II. Mil Med. 2005;170(6):546-49. [PMID:16001610]

25. Tun C, Hogan A, Fitzharris K. Hearing and vestibular dysfunction caused by blast injuries and traumatic brain injuries. Hear J. 2009;62(11):24-26.

26. Lew HL, Weihing J, Myers PJ, Pogoda TK, Goodrich GL. Dual sensory impairment (DSI) in traumatic brain injury (TBI)_An emerging interdisciplinary challenge. NeuroRehabilitation. 2010;26(3):213-22. [PMID:20448311]

27. Lew HL, Poole JH, Vanderploeg RD, Goodrich GL, Dekelboum S, Guillory SB, Sigford B, Cifu DX. Program development and defining characteristics of returning military in a VA Polytrauma Network Site. J Rehabil Res Dev. 2007; 44(7):1027-34. [PMID:18075959] http://dx.doi.org/10.1682/JRRD.2007.05.0073

28. Lew HL, Jerger JF, Guillory SB, Henry JA. Auditory dysfunction in traumatic brain injury. J Rehabil Res Dev. 2007; 44(7):921-28. [PMID:18075949] http://dx.doi.org/10.1682/JRRD.2007.09.0140

29. Fausti SA, Wilmington DJ, Gallun FJ, Myers PJ, Henry JA. Auditory and vestibular dysfunction associated with blastrelated traumatic brain injury. J Rehabil Res Dev. 2009; 46(6):797-810. [PMID:20104403] http://dx.doi.org/10.1682/JRRD.2008.09.0118

30. Weichel ED, Colyer MH, Ludlow SE, Bower KS, Eiseman AS. Combat ocular trauma visual outcomes during Operations Iraqi and Enduring Freedom. Ophthalmology. 2008; 115(12):2235-45. [PMID:19041478] http://dx.doi.org/10.1016/j.ophtha.2008.08.033

31. Mader TH, Carroll RD, Slade CS, George RK, Ritchey JP, Neville SP. Ocular war injuries of the Iraqi Insurgency, January-September 2004. Ophthalmology. 2006;113(1):97-104. [PMID:16290048] http://dx.doi.org/10.1016/j.ophtha.2005.07.018

32. Ari AB. Eye injuries on the battlefields of Iraq and Afghanistan: public health implications. Optometry. 2006;77(7): 329-39. [PMID:16814236] http://dx.doi.org/10.1016/j.optm.2006.03.015

33. Green W, Ciuffreda KJ, Thiagarajan P, Szymanowicz D, Ludlam DP, Kapoor N. Accommodation in mild traumatic brain injury. J Rehabil Res Dev. 2010;47(3):183-99. [PMID:20665345] http://dx.doi.org/10.1682/JRRD.2009.04.0041

34. Goodrich GL, Kirby J, Cockerham G, Ingalla SP, Lew HL. Visual function in patients of a polytrauma rehabilitation center: A descriptive study. J Rehabil Res Dev. 2007; 44(7):929-36. [PMID:18075950] http://dx.doi.org/10.1682/JRRD.2007.01.0003

35. Hoffer ME, Balaban C, Gottshall K, Balough BJ, Maddox MR, Penta JR. Blast exposure: vestibular consequences and associated characteristics. Otol Neurotol. 2010;31(2):
232-36. [PMID:20009782]

http://dx.doi.org/10.1097/MAO.0b013e3181c993c3

36. Hoffer ME, Donaldson C, Gottshall KR, Balaban C, Balough BJ. Blunt and blast head trauma: different entities. Int Tinnitus J. 2009;15(2):115-18. [PMID:20420334]

37. Smith SL, Bennett LW, Wilson RH. Prevalence and characteristics of dual sensory impairment (hearing and vision) in a veteran population. J Rehabil Res Dev. 2008;45(4):597-609. [PMID:18712645] http://dx.doi.org/10.1682/JRRD.2007.02.0023

38. Lew HL, Kraft M, Pogoda TK, Amick MM, Woods P, Cifu DX. Prevalence and characteristics of driving difficulties in Operation Iraqi Freedom/Operation Enduring Freedom combat returnees. J Rehabil Res Dev. 2011;48(8):913-25.

[PMID:22068370]

http://dx.doi.org/10.1682/JRRD.2010.08.0140

39. Crews JE, Campbell VA. Vision impairment and hearing loss among community-dwelling older Americans: implications for health and functioning. Am J Public Health. 2004; 94(5):823-29. [PMID:15117707] http://dx.doi.org/10.2105/AJPH.94.5.823

40. Campbell VA, Crews JE, Moriarty DG, Zack MM, Blackman DK. Surveillance for sensory impairment, activity limitation, and health-related quality of life among older adults-United States, 1993-1997. MMWR CDC Surveill Summ. 1999;48(8):131-56. [PMID:10634273]

41. Brennan M, Su YP, Horowitz A. Longitudinal associations between dual sensory impairment and everyday competence among older adults. J Rehabil Res Dev. 2006;43(6): 777-92. [PMID:17310427] http://dx.doi.org/10.1682/JRRD.2005.06.0109

42. Brennan M, Horowitz A, Su YP. Dual sensory loss and its impact on everyday competence. Gerontologist. 2005; 45(3):337-46. [PMID:15933274]

http://dx.doi.org/10.1093/geront/45.3.337

43. U.S. General Accounting Office. VA health care: mild traumatic brain injury screening and evaluation implemented for OEF/OIF veterans, but challenges remain. GAO-08-276. Washington (DC): U.S. General Accounting Office; 2008. p. 1-55.

44. Kay T, Harrington DE, Adams R, Anderson T, Berrol S, Cicerone K, Dahlberg C, Gerber D, Goka R, Harley P, Hilt J, Horn L, Lemhkuhl D, Malec J; Mild Traumatic Brain Injury Committee of the Head Injury Interdisciplinary Special Interest Group of the American Congress of Rehabilitation Medicine. Definition of mild traumatic brain injury. J Head Trauma Rehabil. 1993;8(3):86-87. http://dx.doi.org/10.1097/00001199-199309000-00010

45. Department of Veterans Affairs and Department of Defense. VA/DOD Clinical Practice Guideline for management of concussion/mild traumatic brain injury. Washington (DC): Department of Veterans Affairs and Department of Defense; 2009. p. 1-112. 
46. Iverson KM, Hendricks AM, Kimerling R, Krengel $M$, Meterko M, Stolzmann KL, Baker E, Pogoda TK, Vasterling JJ, Lew HL. Psychiatric diagnoses and neurobehavioral symptom severity among OEF/OIF VA patients with deploymentrelated traumatic brain injury: a gender comparison. Womens Health Issues. 2011;21(4 Suppl):S210-17. [PMID:21724143] http://dx.doi.org/10.1016/j.whi.2011.04.019

47. National Center for Mental Health Statistics and the Centers for Medicare \& Medicaid Services. The International Classification of Diseases, 9th Revision, Clinical Modification. Washington (DC): National Center for Mental Health Statistics and the Centers for Medicare \& Medicaid Services; 2008.

48. Seal KH, Bertenthal D, Miner CR, Sen S, Marmar C. Bringing the war back home: mental health disorders among 103,788 US veterans returning from Iraq and Afghanistan seen at Department of Veterans Affairs facilities. Arch Intern Med. 2007;167(5):476-82. [PMID:17353495]

http://dx.doi.org/10.1001/archinte.167.5.476

49. Carlson KF, Kehle SM, Meis LA, Greer N, Macdonald R, Rutks I, Sayer NA, Dobscha SK, Wilt TJ. Prevalence, assessment, and treatment of mild traumatic brain injury and posttraumatic stress disorder: a systematic review of the evidence. J Head Trauma Rehabil. 2011;26(2):103-15. [PMID:20631631]

http://dx.doi.org/10.1097/HTR.0b013e3181e50ef1

50. Meterko M, Baker E, Stolzmann KL, Hendricks AM, Cicerone KD, Lew HL. Psychometric assessment of the Neurobehavioral Symptom Inventory-22: the structure of persistent postconcussive symptoms following deployment-related mild traumatic brain injury among veterans. J Head Trauma Rehabil. 2012;27(1):55-62. [PMID:22190009] http://dx.doi.org/10.1097/HTR.0b013e318230fb17

51. Allison L. Imbalance following traumatic brain injury in adults: causes and characteristics. J Neurol Phys Ther. 1999; 23(1):13-18.

52. Department of Veterans Affairs. White House Interagency Council on Women and Girls: Department of Veterans Affairs (VA) women veterans and women VA employees. Washington (DC): Department of Veterans Affairs; 2010. p. 1-18.

53. Department of Defense. Report to the White House Council on Women and Girls. Washington (DC): Department of Defense; 2009. p. 1-54.

54. Harrell MC, Werber Castaneda L, Schirmer P, Hallmark BW, Kavanagh J, Gershwin D, Steinberg P. Assessing the assignment policy for Army women. Santa Monica (CA): National Defense Research Institute; 2007. p. 184.

55. Wijnhoven HA, de Vet HC, Picavet HS. Prevalence of musculoskeletal disorders is systematically higher in women than in men. Clin J Pain. 2006;22(8):717-24. [PMID:16988568] http://dx.doi.org/10.1097/01.ajp.0000210912.95664.53

56. Rustøen T, Wahl AK, Hanestad BR, Lerdal A, Paul S, Miaskowski C. Gender differences in chronic pain-find- ings from a population-based study of Norwegian adults. Pain Manag Nurs. 2004;5(3):105-17. [PMID:15359222] http://dx.doi.org/10.1016/j.pmn.2004.01.004

57. Ladwig KH, Marten-Mittag B, Erazo N, Gündel H. Identifying somatization disorder in a population-based health examination survey: psychosocial burden and gender differences. Psychosomatics. 2001;42(6):511-18. [PMID:11815687] http://dx.doi.org/10.1176/appi.psy.42.6.511

58. Barsky AJ, Peekna HM, Borus JF. Somatic symptom reporting in women and men. J Gen Intern Med. 2001; 16(4):266-75. [PMID:11318929]

http://dx.doi.org/10.1046/j.1525-1497.2001.016004266.x

59. Vanderploeg RD, Belanger HG, Curtiss G. Mild traumatic brain injury and posttraumatic stress disorder and their associations with health symptoms. Arch Phys Med Rehabil. 2009;90(7):1084-93. [PMID:19577020] http://dx.doi.org/10.1016/j.apmr.2009.01.023

60. Street AE, Vogt D, Dutra L. A new generation of women veterans: stressors faced by women deployed to Iraq and Afghanistan. Clin Psychol Rev. 2009;29(8):685-94. [PMID:19766368] http://dx.doi.org/10.1016/j.cpr.2009.08.007

61. Schneiderman AI, Braver ER, Kang HK. Understanding sequelae of injury mechanisms and mild traumatic brain injury incurred during the conflicts in Iraq and Afghanistan: persistent postconcussive symptoms and posttraumatic stress disorder. Am J Epidemiol. 2008;167(12):1446-52.

[PMID:18424429]

http://dx.doi.org/10.1093/aje/kwn068

62. Lippa SM, Pastorek NJ, Benge JF, Thornton GM. Postconcussive symptoms after blast and nonblast-related mild traumatic brain injuries in Afghanistan and Iraq war veterans. J Int Neuropsychol Soc. 2010;16(5):856-66.

[PMID:20682086]

http://dx.doi.org/10.1017/S1355617710000743

63. Lew HL, Vanderploeg RD, Moore DF, Schwab K, Friedman L, Yesavage J, Keane TM, Warden DL, Sigford BJ. Overlap of mild TBI and mental health conditions in returning OIF/ OEF service members and veterans. J Rehabil Res Dev. 2008; 45(3):xi-xvi. [PMID:18629743]

64. Lew HL, Poole JH, Guillory SB, Salerno RM, Leskin G, Sigford B. Persistent problems after traumatic brain injury: The need for long-term follow-up and coordinated care. J Rehabil Res Dev. 2006;43(2):vii-x. [PMID:16847779] http://dx.doi.org/10.1682/JRRD.2006.05.0054

65. Hoge CW, Terhakopian A, Castro CA, Messer SC, Engel CC. Association of posttraumatic stress disorder with somatic symptoms, health care visits, and absenteeism among Iraq war veterans. Am J Psychiatry. 2007;164(1):150-53. [PMID:17202557] http://dx.doi.org/10.1176/appi.ajp.164.1.150 
66. Hill JJ 3rd, Mobo BH Jr, Cullen MR. Separating deploymentrelated traumatic brain injury and posttraumatic stress disorder in veterans: preliminary findings from the Veterans Affairs traumatic brain injury screening program. Am J Phys Med Rehabil. 2009;88(8):605-14. [PMID:19620825] http://dx.doi.org/10.1097/PHM.0b013e3181ae0f83

67. Brenner LA, Ivins BJ, Schwab K, Warden D, Nelson LA, Jaffee M, Terrio H. Traumatic brain injury, posttraumatic stress disorder, and postconcussive symptom reporting among troops returning from Iraq. J Head Trauma Rehabil. 2010; 25(5):307-12. [PMID:20042982] http://dx.doi.org/10.1097/HTR.0b013e3181cada03

68. Castro CA, Hoge CW. Building psychological resiliency and mitigating the risks of combat and deployment stressors faced by soldiers. In: Strategies to Maintain Combat Readiness during Extended Deployments-A Human Systems Approach. The RTO Human Factors and Medicine Panel Symposium; 3-5 Oct 2005; Prague, Czech Republic. Neuilly-sur-Seine (France): NATO Research \& Technology Organisation; 2005.

69. Wall SE, Williams WH, Cartwright-Hatton S, Kelly TP, Murray J, Murray $\mathrm{M}$, Owen A, Turner $\mathrm{M}$. Neuropsychological dysfunction following repeat concussions in jockeys. J Neurol Neurosurg Psychiatry. 2006;77(4):518-20.

[PMID:16543534] http://dx.doi.org/10.1136/jnnp.2004.061044

70. Thériault M, De Beaumont L, Tremblay S, Lassonde M, Jolicoeur P. Cumulative effects of concussions in athletes revealed by electrophysiological abnormalities on visual working memory. J Clin Exp Neuropsychol. 2011;33(1): 30-41. [PMID:20480425] http://dx.doi.org/10.1080/13803391003772873

71. Schatz P, Moser RS, Covassin T, Karpf R. Early indicators of enduring symptoms in high school athletes with multiple previous concussions. Neurosurgery. 2011;68(6):1562-67, discussion 1567. [PMID:21258259] http://dx.doi.org/10.1227/NEU.0b013e31820e382e

72. Thornton AE, Cox DN, Whitfield K, Fouladi RT. Cumulative concussion exposure in rugby players: neurocognitive and symptomatic outcomes. J Clin Exp Neuropsychol. 2008; 30(4):398-409. [PMID:18938678] http://dx.doi.org/10.1080/13803390701443662

73. Iverson GL, Gaetz M, Lovell MR, Collins MW. Cumulative effects of concussion in amateur athletes. Brain Inj. 2004;18(5):433-43. [PMID:15195792] http://dx.doi.org/10.1080/02699050310001617352

74. Guskiewicz KM, McCrea M, Marshall SW, Cantu RC, Randolph C, Barr W, Onate JA, Kelly JP. Cumulative effects associated with recurrent concussion in collegiate football players: the NCAA Concussion Study. JAMA. 2003; 290(19):2549-55. [PMID:14625331] http://dx.doi.org/10.1001/jama.290.19.2549
75. Department of the Army. Standards of medical fitness. Washington (DC): Department of the Army; 2007. p. 1-152.

76. Vanderploeg RD, Belanger HG, Duchnick JD, Curtiss G. Awareness problems following moderate to severe traumatic brain injury: Prevalence, assessment methods, and injury correlates. J Rehabil Res Dev. 2007;44(7):937-50. [PMID:18075951] http://dx.doi.org/10.1682/JRRD.2006.12.0163

77. Sayer NA, Rettmann NA, Carlson KF, Bernardy N, Sigford BJ, Hamblen JL, Friedman MJ. Veterans with history of mild traumatic brain injury and posttraumatic stress disorder: challenges from provider perspective. J Rehabil Res Dev. 2009;46(6):703-16. [PMID:20104400] http://dx.doi.org/10.1682/JRRD.2009.01.0008

78. Sayer NA, Chiros CE, Sigford B, Scott S, Clothier B, Pickett T, Lew HL. Characteristics and rehabilitation outcomes among patients with blast and other injuries sustained during the Global War on Terror. Arch Phys Med Rehabil. 2008; 89(1):163-70. [PMID:18164349] http://dx.doi.org/10.1016/j.apmr.2007.05.025

79. Lew HL, Pogoda TK, Hsu PT, Cohen S, Amick MM, Baker E, Meterko M, Vanderploeg RD. Impact of the "polytrauma clinical triad" on sleep disturbance in a Department of Veterans Affairs outpatient rehabilitation setting. Am J Phys Med Rehabil. 2010;89(6):437-45. [PMID:20489391] http://dx.doi.org/10.1097/PHM.0b013e3181ddd301

80. Lew HL, Otis JD, Tun C, Kerns RD, Clark ME, Cifu DX. Prevalence of chronic pain, posttraumatic stress disorder, and persistent postconcussive symptoms in OIF/OEF veterans: polytrauma clinical triad. J Rehabil Res Dev. 2009; 46(6):697-702. [PMID:20104399]

http://dx.doi.org/10.1682/JRRD.2009.01.0006

Submitted for publication June 3, 2011. Accepted in revised form August 18, 2011.

This article and any supplementary material should be cited as follows:

Pogoda TK, Hendricks AM, Iverson KM, Stolzmann KL, Krengel MH, Baker E, Meterko M, Lew HL. Multisensory impairment reported by veterans with and without mild traumatic brain injury history. J Rehabil Res Dev. 2012;49(7):971-84.

http://dx.doi.org/10.1682/JRRD.2011.06.0099

ResearcherID: Terri K. Pogoda, PhD: F-6243-2012

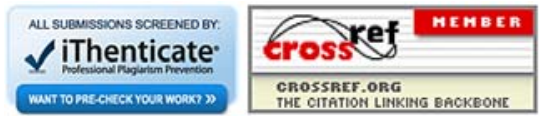


